\title{
Is Real-time Pricing Smart for Consumers?
}

\author{
Boom, Anette; Schwenen, Sebastian
}

Document Version

Final published version

Publication date:

2020

License

Unspecified

Citation for published version (APA):

Boom, A., \& Schwenen, S. (2020). Is Real-time Pricing Smart for Consumers? Department of Economics.

Copenhagen Business School. Working Paper / Department of Economics. Copenhagen Business School No. $12-2020$

Link to publication in CBS Research Portal

\section{General rights}

Copyright and moral rights for the publications made accessible in the public portal are retained by the authors and/or other copyright owners and it is a condition of accessing publications that users recognise and abide by the legal requirements associated with these rights.

Take down policy

If you believe that this document breaches copyright please contact us (research.lib@cbs.dk) providing details, and we will remove access to the work immediately and investigate your claim. 
Copenhagen

Business School

HAN D ELSH ØJSKO LEN

\section{Department of Economics}

Copenhagen Business School

Working paper 12-2020

\begin{tabular}{|c|}
\hline Is Real-time Pricing \\
Smart for \\
Consumers? \\
Anette Boom \\
Sebastian Schwenen
\end{tabular}

Department of Economics - Porcelænshaven 16A, 1. DK-2000 Frederiksberg 


\title{
Is Real-time Pricing Smart for Consumers?
}

\author{
Anette Boom* \\ Copenhagen Business School \\ Sebastian Schwenen ${ }^{\dagger}$ \\ Technical University of Munich and DIW Berlin
}

July 2020

\begin{abstract}
We examine the effects of real-time pricing on welfare and consumer surplus in electricity markets. We model consumers on real-time pricing who purchase electricity on the wholesale market. A second group of consumers contracts with retailers and pays time-invariant retail prices. Electricity generating firms compete in supply functions. Increasing the number of consumers on real-time pricing increases welfare and consumer surplus of both types of consumers. Yet, risk averse consumers on traditional timeinvariant retail prices are always better off. Collectively, our results point to a public good nature of demand response in power markets when consumers are risk-averse.
\end{abstract}

Keywords: Electricity; Real-time Pricing; Market Power; Efficiency.

JEL-Code: D42, D43, D44, L11, L12, L13.

*Corresponding author: Copenhagen Business School, Department of Economics, Porcelanshaven 16 A, DK-2000 Frederiksberg, e-mail: ab.eco@cbs.dk.

†Technical University of Munich, School of Management, and DIW Berlin (Germany). Email: sebastian.schwenen@tum.de. 


\section{Introduction}

Advances in information technology and the rising need for energy-efficient consumption have increased the use of smart metering in electricity markets. Traditionally, households could only observe their total consumption levels and were billed on a monthly or annual base. While smarter metering devices allow for efficiency gains through demand response to real-time prices, the diffusion of time-varying pricing schemes has, however, been slow (e.g., Joskow and Wolfram, 2012; European Commission, 2014). Despite massive deployment initiatives in the US over the last decade, only about $4 \%$ of residential costumers signed contracts with dynamic prices (Borenstein and Bushnell, 2019). ${ }^{1}$

In this paper, we propose a model for analyzing participation incentives and welfare effects of real-time pricing (RTP). To explain the slow diffusion of RTP that is observed in many power markets across the globe, we formally introduce two candidate arguments into the existing analysis: risk-averse consumers and strategic firms. Our model builds on the supposition that risk-averse consumers may experience a loss in utility from volatile wholesale prices and thus shy away from real-time pricing. Furthermore, we examine the interaction of RTP with strategic firms, where on the one hand mark-ups should decline with more elastic demand. On the other hand, consumers who buy wholesale give up on "hedging" via the fixed retail price, which for high demand levels may lead to high prices on the wholesale market.

That prices should fluctuate if output cannot easily be adapted to changes in demand is well-established in the peak-load pricing literature. ${ }^{2}$ Consistent with this idea, Borenstein and Holland (2005) show that in competitive electricity markets with risk-neutral consumers, time-varying retail prices indeed improve overall efficiency.

\footnotetext{
${ }^{1}$ Sweden, as another case, achieved a smart meter coverage of $100 \%$ already in 2009, while years later still only about $5 \%$ of electricity suppliers offered contracts with real-time prices (Campillo et al., 2016).

${ }^{2}$ See Crew et al. (1995) for a comprehensive review on the implications of peak-load pricing.
} 
To introduce strategic firms and risk-averse consumers into the analysis of real-time pricing, we draw from canonical supply function models for electricity wholesale markets (e.g., Wilson, 1979; Klemperer and Meyer, 1989; Green and Newbery, 1992; Baldick et al., 2004; Hortacsu and Puller, 2008; Holmberg and Newbery, 2010). On the demand side, we distinguish between elastic wholesale demand from consumers on RTP and wholesale demand from retail firms, which buy electricity on behalf of their customers. The retail sector is perfectly competitive. Consumers who are not on real-time pricing need to contract with retailers before their own and the aggregate level of demand is known. As these traditional consumers are on fixed pricing schemes, they will eventually pay the same per-unit price irrespective of the level of demand.

Our findings show that RTP yields clear benefits but that RTP is not incentive compatible. We first show that, in line with the existing literature (Borenstein and Holland, 2005; Poletti and Wright, 2020), an increase in the ratio of consumers on RTP increases social welfare. Furthermore, the marginal consumer who opts for RTP causes a positive externality on both, other RTP consumers and traditional consumers on fixed prices. The underlying mechanism is that, as the share of RTP consumers increases, the average wholesale price decreases, and so does the competitive retail price. The lower retail price benefits traditional consumers, who at the same time are not exposed to volatile market prices. We find that also the risk-averse consumers already on RTP benefit from the marginal household switching to RTP, as real-time wholesale prices likewise become less volatile. However, we show the marginal household opting for RTP is worse off, and thus has no incentives to switch to RTP. Because welfare is higher with collective RTP contracts but each consumer is individually better off when his or her neighbor switches, our results point to a public good nature of real-time pricing when consumers are risk-averse.

Our results contribute to several strands of literature. First, we contribute to the vast literature on retail market design (e.g., Joskow and Tirole, 2006, 2007). This literature 
focuses on attainable (second-best) welfare outcomes for different settings of price-sensitive and price-insensitive consumers, and under different rationing regimes, taxes, and subsidy schemes. Our contribution to this debate on retail market efficiency is to introduce riskaverse consumers, and to show how equilibrium retail and wholesale prices impact consumer incentives to either react to or to insure against time-varying wholesale prices. ${ }^{3}$

More closely, we contribute to the theory literature on real-time pricing. In a seminal paper, Borenstein and Holland (2005) illustrate that RTP increases market efficiency and show that consumers who switch to RTP (i) are better off as compared to paying fixed retail prices, (ii) exercise a positive externality on consumers who remain on fixed retail prices, and (iii) harm incumbent RTP consumers. In this context, we find that when accounting for risk-aversion, the marginal consumer on RTP does not harm but instead benefit incumbent RTP consumers. This finding results from introducing risk-aversion: More RTP consumers flatten the price volatility and hence decrease risk for incumbent RTP consumers. In a recent article, Poletti and Wright (2020) also identify positive externalities for incumbent RTP consumers and attribute this effect to the reduction in market power. In our setting, while RTP likewise reduces market power, the positive effect on incumbent RTP consumers also holds for cases of perfect competition and thus can solely arise from risk-aversion.

Furthermore, we show that the above gains of RTP that the literature has so far identified can be hard to realize. This is because, when explicitly accounting for risk aversion, consumers are better off on fixed prices and thus have no incentives to opt into RTP contracts. Consequently, the positive externality on remaining traditional consumers with fixed prices will not materialize because no consumer has an incentive to switch to RTP. Collectively, our results show that the benefits of real-time pricing grow with strategic firms, yet achieving these benefits is not incentive-compatible when consumers are risk-averse.

\footnotetext{
${ }^{3}$ As in Borenstein and Holland (2005), we model uniform retail prices whereas Joskow and Tirole (2006, 2007) and Poletti and Wright (2020) consider two-part tariffs.
} 
Last, we connect to the empirical literature on the adoption of real-time pricing. ${ }^{4}$ The extant literature has documented efficiency gains with RTP, albeit at low or moderate levels (Holland and Mansur, 2006; Léautier, 2014). Furthermore, Horowitz and Lave (2014) and Hung et al. (2020) find that different time-of-use pricing schemes can have different distributional implications. Qiu et al. (2017) present empirical evidence from about 400 households in California and Arizona, US, suggesting that more risk-averse consumers are less likely to participate in time-of-use pricing programs. With Qiu et al. (2017) documenting that risk-aversion is present and relevant for consumer decisions, we view our model as a starting point to analyze the equilibrium effects of risk-aversion, its impact on equilibrium retail and wholesale prices, and thus on the potentials for further market diffusion and the design of RTP.

The remainder is organized as follows. The next section presents the model setup. Section three derives the model outcome and presents wholesale and retail market equilibria. In section four, we present comparative statics on the level of real-time pricing and derive welfare gains and participation incentives. Section five discusses regulatory implications and section six concludes.

\section{Model setup}

We represent the demand side as a unit mass of consumers. Each consumer can be one of two types. First, consumers can be on real-time pricing schemes (RTP consumers). We denote the share of RTP consumers as $t$. Second, consumers can be on traditional metering and fixed pricing schemes. We relate to these consumers as traditional consumers or consumers on fixed prices. These consumers account for the share of $(1-t)$ of demand. The preferences

\footnotetext{
${ }^{4}$ Notice that we study the decision to opt into real-time pricing, rather than the response to time-varying prices given that consumers are on RTP schemes. Empirical and experimental research reports heterogeneous reactions to price and non-price information in real-time (e.g., Patrick and Wolak, 2001; Taylor et al., 2005; Boisvert et al., 2007; Zarnikau and Hallett, 2008; Allcott, 2011; Jessoe and Rapson, 2014; Wolak, 2015).
} 
of both types of consumers feature risk-aversion and are modeled by the consumer surplus function

$$
V(x, \varepsilon, p)=x-\varepsilon-\frac{(x-\varepsilon)^{2}}{2}-p x
$$

where $p$ is the electricity price (which may follow RTP pricing or be a fixed retail price), $x$ the electricity consumed and $\varepsilon$ a shock that affects all consumers alike. ${ }^{5}$ The demand shock is drawn from a uniform distribution on $[0,1]$. Maximizing surplus with respect to the consumed electricity $x$ yields consumer demand of

$$
x(p, \varepsilon)=\max \{1+\varepsilon-p, 0\} .
$$

On the supply side, a number of $n>2$ symmetric electricity generating firms compete on the wholesale market. We study competition in linear supply functions and assume that each firm $i$ has linear increasing marginal costs, given by

$$
c\left(q_{i}\right)=a+b q_{i}
$$

with $a \geq 0$ and $b>0$ being cost parameters and $q_{i}$ being firm $i$ 's output. We consider a setting in which each firm $i$ submits its supply function $S_{i}(p)$ before realized demand (the realization of $\varepsilon$ ) is publicly known. ${ }^{6}$

The wholesale market clears as a uniform price auction. At the uniform clearing price, wholesale supply equals realized wholesale demand, and all supply at prices below the clearing price is dispatched and receives this price. Note that the wholesale demand is made up of the aggregate of the two consumer types. Since the total demand of traditional consumers depends on the retail price, also aggregate wholesale demand depends not only on the wholesale price but also on the retail price, denoted by $r$.

\footnotetext{
${ }^{5}$ The demand side of our model is the same as in Boom (2009) and Boom and Buehler (2020).

${ }^{6}$ The supply side of the market is similar to Baldick et al. (2004) and Hortacsu and Puller (2008).
} 
On the retail market, several retailers compete à la Bertrand. Consumers without a smart meter subscribe to the retailer with the lowest retail price $r$. At this stage, their actual level of demand is still uncertain. For tractability, we assume zero retailing costs. The retailers' marginal costs at the contracting stage are therefore equal to the expected wholesale price at which they buy electricity. After the retail market clears and having observed the actual level of demand (the realization of $\varepsilon$ ), retailers announce their customers' demand for electricity to the wholesale auction. Note that retailers with supply obligations do not go out of business if their marginal costs (the equilibrium wholesale market price $p^{*}$ ) exceeds the retail price. Instead, we assume that retailers have to break even in expectation. Put differently, retailers have to break even considering the entire range of demand shocks (say, over a year).

\begin{tabular}{|c|c|c|c|c|c|}
\hline Retailers & $\begin{array}{c}\text { Consumers } \\
\text { not on } \\
\text { RTP }\end{array}$ & Generators & Nature & $\begin{array}{l}\text { Consumers } \\
\text { on RTP and } \\
\text { retailers }\end{array}$ & $\begin{array}{l}\text { Market } \\
\text { Operator }\end{array}$ \\
\hline $\begin{array}{c}\text { compete } \\
\text { in retail } \\
\text { prices }\end{array}$ & $\begin{array}{l}\text { subscribe } \\
\text { to retailers }\end{array}$ & $\begin{array}{l}\text { submit } \\
\text { supply } \\
S_{i}(p)\end{array}$ & $\begin{array}{c}\text { draws } \\
\text { demand }\end{array}$ & $\begin{array}{l}\text { announce } \\
\text { demand } \mathrm{w}\end{array}$ & $\begin{array}{c}\text { determines } \\
\text { vholesale price } \\
p^{*}\end{array}$ \\
\hline
\end{tabular}

Figure 1: Timing of the model.

Figure 1 summarizes the timing of the model. As shown, in the first stage of the game, before the level of demand is known, retailers set their retail prices for customers without real-time meters. These customers contract with the retailer who offers the lowest price. ${ }^{7}$ Subsequently, generators submit their supply functions to the market. We model this stage as a one-shot game, whereas in real-world settings this bidding process and the market clearing occur repeatedly. Prior to market clearing, nature draws the demand shock $\varepsilon$ and demand is known to the RTP consumers and to the retailers, who then bid their demand

\footnotetext{
${ }^{7}$ The contract is a service contract and implies that the costumers are provided with as much electricity as they want, as long as the retailer does not go out of business. Rationing rules as discussed in Joskow and Tirole (2007) are not part of the contract and are also not very common for residential households.
} 
or the demand of their costumers into the market. Finally, the market operator determines the wholesale electricity price $p^{*}$ as described above. We search for the subgame perfect equilibrium of this game. ${ }^{8}$

\section{Wholesale and retail prices}

We begin our analysis with the wholesale market stage. After deriving the equilibrium outcome at the wholesale market (given retail prices and given levels of RTP), we subsequently determine the equilibrium retail price.

\subsection{The wholesale market}

As argued, by the time electricity generating firms decide on their supply function, they have no information on the realization of the demand shock and instead have to form a prior. We therefore first investigate wholesale market demand and show that, given the above consumer preferences, demand shocks shift the demand curve in a parallel fashion.

Recall that the group of traditional consumers buys electricity via their respective retailer and pays the pre-determined retail price $r$. Given any $r$, retailers collectively then demand a fixed volume of electricity, $(1-t)(1+\varepsilon-r)$. In contrast, the group of RTP consumers has total demand of $t(1+\varepsilon-p)$ with $p$ being the wholesale price. In sum, the wholesale demand therefore can be written as

$$
D(p, r, t, \varepsilon)=1+\varepsilon-t p-(1-t) r
$$

Notice that the demand function in equation (4) results from our setting with a unit mass

\footnotetext{
${ }^{8}$ It is equivalent to assume a timing where nature draws demand before firms submit their bids, but the demand realization remains private information to the demand side, and simultaneous bidding of supply and demand occurs with demand knowing and supply not knowing $\varepsilon$.
} 
of consumers. As can be seen, the demand shock causes parallel shifts in demand. Prior to submitting their supply function, firms have perfect knowledge of all other parameters, in particular of $r$ and $t$ and face uncertain demand as in equation (4).

With $n$ symmetric firms seeking to sell electricity, the wholesale clearing price $p^{*}$ must then satisfy

$$
\sum_{i}^{n} S_{i}\left(p^{*}\right)=D\left(p^{*}, r, t, \varepsilon\right)
$$

and each firm's realized profits become

$$
\pi_{i}=S_{i}\left(p^{*}\right) p^{*}-C_{i}\left(S_{i}\left(p^{*}\right)\right)
$$

where $C_{i}$ is the total cost function of firm $i$.

Because demand is unknown at the time of bidding, firm $i$ faces uncertainty on the clearing price in equation (5). As common in the literature (e.g., Wilson, 1979; Hortacsu and Puller, 2005, 2008), we therefore translate the randomness in demand to randomness in price. Denoting the cumulative distribution function of the market clearing price as $H_{i}\left(p, S_{i}\right) \equiv \operatorname{Pr}\left(p^{*}<p \mid S_{i}\right)$, firm's maximize expected profits as

$$
\max _{S_{i}(p)} \mathbb{E}\left(\pi_{i}\right)=\int_{\underline{p}}^{\bar{p}}\left[S_{i}(p) p-C_{i}\left(S_{i}(p)\right)\right] d H_{i}\left(p \mid S_{i}\right) .
$$

The support of prices is implicitly defined through the support of demand shocks. The Euler-Lagrange first-order condition yields

$$
p-c\left(S_{i}^{*}(p)\right)=S_{i}^{*}(p) \frac{H_{S}\left(p, S_{i}^{*}(p)\right)}{H_{p}\left(p, S_{i}^{*}(p)\right)} .
$$

The optimality condition in (8) states that firm $i$ 's optimal supply function determines the mark-up over marginal costs, on the left hand side, as a function of total supply multiplied by the ratio of $H_{S}$ to $H_{p}$, which are derivatives of $H$ with respect to supply and price. A 
proof of this derivation can be found in Hortacsu and Puller (2008) and in more detail in Hortacsu and Puller (2005).

To interpret the optimality condition, note that $H_{p}$ is the probability density function of price and therefore must be positive. $H_{S}$ likewise is positive because with additional supply the likelihood that price is below any given value increases. Using the demand function as represented in equation (4) and the firms' marginal cost function $c\left(q_{i}\right)=a+b q_{i}$, we can compute the equilibrium supply functions.

Proposition 1 The equilibrium supply function $S_{i}^{*}$ depends on the share of RTP consumers:

$$
\begin{gathered}
S_{i}^{*}(p)=\beta_{t}(p-a) \text { with } \\
\beta_{t}=\frac{n-2-b t+\sqrt{(n-2)^{2}+2 b n t+b^{2} t^{2}}}{2 b(n-1)}
\end{gathered}
$$

where the subscript $t$ is shorthand notation to indicate that the equilibrium slope parameter $\beta_{t}$ depends on the share of RTP consumers.

Proof: Using that $\frac{H_{S}\left(p, S_{i}^{*}\right)}{H_{p}\left(p, S_{i}^{*}\right)}$ is the inverse of the slope of firm $i$ 's residual demand (Hortacsu and Puller, 2008) and assuming linear symmetric supply functions of the form

$$
S_{i}(p)=\alpha+\beta p,
$$

the first order condition (8) translates into

$$
\begin{gathered}
p-[a+b(\alpha+\beta p)]=(\alpha+\beta p) \frac{1}{(n-1) \beta+t} \\
\Longleftrightarrow[p(1-b \beta)-(a+b \alpha)][\beta(n-1)+t]=\alpha+\beta p .
\end{gathered}
$$


Thus, $\alpha$ and $\beta$ must solve the following set of equations

$$
\begin{aligned}
\alpha & =-(a+b \alpha)[\beta(n-1)+t], \\
\beta & =(1-b \beta)[\beta(n-1)+t],
\end{aligned}
$$

which yields $\beta=\beta_{t}$ from equation (10) and $\alpha=-a \beta_{t}$.

Without any RTP consumers, meaning $t=0$, the bid functions reduce to the analytical solution with inelastic demand in Hortacsu and Puller (2005). Also notice that, as common for this type of equilibrium, Proposition 1 holds for $n>2$. From the above proposition, it is straightforward to show how the firms' supply functions change if more consumers are on RTP.

Corollary 1 The slope of firm i's supply function increases if the ratio $t$ of consumers on RTP increases, i.e.,

$$
\frac{\partial \beta_{t}}{\partial t}>0
$$

always holds.

Corollary 1 illustrates that for a higher share $t$ of RTP consumers with elastic wholesale demand, firms submit more aggressive supply functions and increase their supply at any price level. ${ }^{9}$

The equilibrium wholesale market price must satisfy the market clearing condition in equation (5), implying

$$
n \beta_{t}(p-a)=1+\varepsilon-t p-(1-t) r .
$$

Rearranging and solving for $p$ yields the equilibrium wholesale price as a function of the

\footnotetext{
${ }^{9}$ In contrast to the analytical solution for the slope parameter in Hortacsu and Puller (2008), we apply downward sloping demand which leads to the quadratic term in the slope parameter. For more supply function specifications, see Baldick et al. (2004).
} 
retail price and the demand shock, given the share of RTP consumers,

$$
p^{*}(\varepsilon, r, t)=\frac{1+\varepsilon-(1-t) r+a \beta_{t} n}{\beta_{t} n+t} .
$$

\subsection{The retail market}

Next, we derive equilibrium retail prices for a given share of RTP consumers. Retailers compete in prices and do not face any other retail costs than the price they pay for electricity on the wholesale market. Therefore, all retailers compete in retail prices down to a level where they do not generate positive profits in expectation. From this idea we can derive the following proposition which describes the retail price in equilibrium.

Proposition 2 There is a unique subgame perfect equilibrium in which all retailers charge $r^{*}=\mathbb{E}\left[p^{*}(\varepsilon)\right]$ and the equilibrium retail price is given by

$$
r^{*}=\frac{3+2 a \beta_{t} n}{2\left(1+\beta_{t} n\right)}
$$

Proof: Substituting $p^{*}(\varepsilon, r, t)$ in equation (13) into $r^{*}=\mathbb{E}\left[p^{*}(\varepsilon)\right]$ one obtains

$$
\mathbb{E}\left[p^{*}(\varepsilon)\right]=\int_{0}^{1} p^{*}(\varepsilon, \cdot) d \varepsilon=\frac{3+2\left[a \beta_{t} n-(1-t) r\right]}{\beta_{t} n+t}=r .
$$

Solving this equation for $r$ yields the equilibrium retail price given in equation (14).

With the equilibrium retail price at hand, we finally obtain the equilibrium wholesale price by substituting $r^{*}$ from (14) into $p^{*}(\varepsilon, r)$ in equation (13) and obtain

$$
p^{*}\left(\varepsilon, r^{*}, t\right)=a+\frac{3-2 a}{2\left(1+\beta_{t} n\right)}+\frac{2 \varepsilon-1}{2\left(t+\beta_{t} n\right)} .
$$

So far, we did not specify bounds on the production costs and hence a bound on the 
market price. Recalling equation (2), we in particular want to rule out negative demand in our analysis. To specify feasible cost parameters for our model, we must rule out equilibrium prices $p^{*}$ and $r^{*}$ which exceed the maximum demand of $1+\varepsilon$ for all $\varepsilon \in[0,1]$. This condition is satisfied for all demand levels $f(\varepsilon, t)$ if

$$
f(\varepsilon, t) \equiv 1+\varepsilon-p^{*}\left(\varepsilon, r^{*}, t\right) \geq 0
$$

holds for all $\varepsilon \in[0,1]$. The sufficient condition for this inequality to hold is ${ }^{10}$

$$
b \leq \bar{b}=\frac{n(n-2)}{n-1} \text { and } a<\bar{a}=1 .
$$

The intuition is straightforward: The first condition states that the cost function cannot be as convex to generate equilibrium prices above maximum demand. This condition becomes weaker as the number of firms increases, because the convexity of the cost function becomes less important when more firms each produce smaller quantities. Second, production costs must be below demand. Specifically, the constant part of marginal cost, $a$, must be below demand at a price of zero, i.e., $a<\min [1+\varepsilon-p]=1$ for the lowest possible price $(p=0)$ and lowest demand shock $(\varepsilon=0)$. In sum, these conditions assure that both RTP and retail customers are always active.

Having characterized the equilibrium wholesale and retail prices, we can derive the following corollary results.

\section{Corollary 2 Higher shares of RTP consumers}

(i) decrease the retail and the expected wholesale price, $\frac{\partial r^{*}}{\partial t}=\frac{\mathbb{E}\left[p^{*}(\varepsilon)\right]}{\partial t}<0$,

(ii) decrease the volatility of the wholesale price, $\frac{\partial p^{*}}{\partial \varepsilon \partial t}<0$, and

\footnotetext{
${ }^{10}$ Formally, these two conditions ensure that inequality (16) above holds at $\varepsilon=0$ as well as at any larger demand shock, i.e., $\partial f / \partial \varepsilon>0$ independent of the level of $t \in[0,1]$. Since $f(0, t)>0$ always holds, $\partial f / \partial \varepsilon>0$ is sufficient to have positive demand for all consumers.
} 
(iii) can increase or decrease the realized wholesale price.

The first two results (i) and (ii) in Corollary 2 follow directly from taking the derivatives. Incumbent RTP consumers benefit in that the expected wholesale price and its volatility decreases. Retail consumers benefit because the retail price decreases.

To see the ambiguous effect on the realized wholesale price, note that more consumers on RTP can increase wholesale demand in some cases and hence also the equilibrium wholesale

price. Specifically, the wholesale demand changes by $\frac{\partial D\left(\varepsilon, r^{*}, t\right)}{\partial t}=r^{*}(t)-p-(1-t) \frac{\partial r^{*}(t)}{\partial t}$. The first two terms show that total demand changes because the marginal household changing to RTP now demands at a price $p$ instead of $r^{*}(t)$. Therefore, for any wholesale price below the retail price, demand increases at this price due to the additional household on RTP. In contrast, demand decreases for all wholesale prices above the retail price, because the additional household stops demanding quantities at $r^{*}$ and now buys less at the higher wholesale price. The last term again shows the positive externality on traditional consumers: the marginal household opting into RTP decreases the retail price and hence the fraction $(1-t)$ of consumers increases retail demand. Consequently, where increases in demand outweigh additional supply (recall that $\frac{\partial \beta_{t}}{\partial t}>0$ ), the wholesale price can increase.

While realized prices can change in either direction, the finding that retail prices and the wholesale price volatility strictly decrease suggests that externalities from RTP exist towards both consumers groups.

\section{Consumer surplus and incentives to switch to RTP}

In this section, we use the equilibrium model above for comparative statics on the level of real-time pricing. We are interested in effects on consumer surplus and the resulting incentives to switch to RTP. To explore regulatory implications, we also provide results on overall welfare. 
We first derive expressions for consumers surplus and welfare, where we neglect competitive retailers, who by design have zero profits and do not impact surplus. Yet, their competitive retail price, its changes in $t$, and repercussions on the wholesale market demand co-determine welfare and consumer surplus. Using the surplus function in equation (1) and the demand by RTP consumers of $x^{*}=x^{*}\left(p^{*}\right)=1+\varepsilon-p^{*}$, we can compute the consumer surplus for this group as

$$
C S_{R T P}=V\left[x^{*}\left(p^{*}\right)\right]-p^{*} x^{*}\left(p^{*}\right) .
$$

Similarly, for traditional consumers with fixed retail prices who demand $x^{*}=x^{*}\left(r^{*}\right)=$ $1+\varepsilon-r^{*}$, surplus is given by

$$
C S_{F P}=V\left[x^{*}\left(r^{*}\right)\right]-r^{*} x^{*}\left(r^{*}\right) .
$$

Total consumer surplus in the market therefore is

$$
C S=t C S_{R T P}+(1-t) C S_{F P}
$$

Welfare follows from the above and is given by

$$
W=t V\left[x^{*}\left(p^{*}\right)\right]+(1-t) V\left[x^{*}\left(r^{*}\right)\right]-C\left(t x^{*}\left(p^{*}\right)+(1-t) x^{*}\left(r^{*}\right)\right),
$$

where $C$ is the market-wide cost function. Recalling marginal costs in equation (3), total costs become

$$
C=n\left[\frac{a\left[t x^{*}\left(p^{*}\right)+(1-t) x^{*}\left(r^{*}\right)\right]}{n}+\frac{b}{2}\left(\frac{t x^{*}\left(p^{*}\right)+(1-t) x^{*}\left(r^{*}\right)}{n}\right)^{2}\right],
$$

with $t x^{*}\left(p^{*}\right)+(1-t) x^{*}\left(r^{*}\right)=1+\varepsilon-t p^{*}-(1-t) r^{*}$.

Next, we establish a set of results on how real-time pricing impacts welfare and consumer 
surplus. We obtain our results from substituting the equilibrium retail and wholesale price in equation (14) and (15) into the relevant expressions above. As we are interested in the incentives to switch to RTP contracts, and given that consumers decide on contracts before market clearing, we investigate expected welfare and surplus by integrating over $\varepsilon$.

Expected Welfare. The expected welfare depends on the cost parameters, on the supply slope, and on the number of firms. Computing expected welfare yields

$$
\mathbb{E}(W)=\frac{4(a-3) a \beta_{t} n\left(2-\beta_{t}(b-n)\right)+\beta_{t} n\left(8-\beta_{t}(9 b-4 n)\right)-5}{8\left(1+\beta_{t} n\right)^{2}}-\frac{b \beta_{t}^{2} n+t}{24\left(\beta_{t} n+t\right)^{2}}
$$

Notice that the expected welfare depends directly and indirectly (via its impact on the slope of the supply function $\beta_{t}$ ) on the share $t$ of RTP costumers. Using equation (22), we can state the following Proposition on expected welfare.

Proposition 3 The expected welfare increases in the ratio of consumers on real-time pricing.

Proof: Taking the derivative of $(22)$ with respect to $t$ yields

$$
\begin{gathered}
\frac{d \mathbb{E}(W)}{d t}=\frac{\partial \mathbb{E}(W)}{\partial t}+\frac{\partial \mathbb{E}(W)}{\partial \beta_{t}} \frac{\partial \beta_{t}}{\partial t} \\
\Longleftrightarrow \frac{d \mathbb{E}(W)}{d t}=\frac{\beta_{t} n\left(2 b \beta_{t}-1\right)+t}{24\left(\beta_{t} n+t\right)^{3}}+\frac{n\left(b \beta_{t}-1\right)\left(t-3(3-2 a)^{2}\right)}{12\left(\beta_{t} n+1\right)^{3}} \frac{\partial \beta_{t}}{\partial t}>0 .
\end{gathered}
$$

The inequality holds because, using $\beta_{t}$ from equation (10), it can easily be shown that $b \beta_{t}<1<2 b \beta_{t}$. Using $a<1$ from equation (17) then implies that both nominators must be positive. Together with $\frac{\partial \beta_{t}}{\partial t}>0$ from Corollary 1 , the inequality follows.

That welfare increases in the share of consumers on real-time pricing corroborates existing findings in, e.g., Borenstein (2005) and Poletti and Wright (2020), and shows that this result holds when investigating outcomes within supply function models and when accounting for risk-averse consumers. Proposition 3 also confirms that from a regulatory perspective, it remains desirable to increase the use of real-time pricing contracts. In the following, we 
probe into consumer surplus and investigate whether the welfare maximum as shown above (i.e., a market of only RTP consumers) is indeed incentive compatible when consumers are risk-averse.

Consumer surplus. The expected surplus of traditional consumers on fixed retail prices becomes

$$
\mathbb{E}\left(C S_{F P}\right)=\frac{2 \beta_{t} n\left(2(1-(3-a) a) \beta_{t} n-5\right)-5}{8\left(\beta_{t} n+1\right)^{2}} .
$$

Conversely, the expected surplus of consumers on RTP can be written in a similar fashion and only differs by a constant that depends on $\beta_{t}, n$, and $t$, so

$$
\mathbb{E}\left(C S_{R T P}\right)=\mathbb{E}\left(C S_{F P}\right)+\frac{1-2\left(\beta_{t} n+t\right)}{24\left(\beta_{t} n+t\right)^{2}} .
$$

For tractability, we denote the difference in expected consumer surplus between these two groups as $\Delta\left(\beta_{t}, n, t\right)$ so that in what follows we can write $\mathbb{E}\left(C S_{R T P}\right)=\mathbb{E}\left(C S_{F P}\right)+\Delta\left(\beta_{t}, n, t\right)$.

Proposition 4 The expected consumer surplus of consumers on real-time pricing and of consumers with fixed retail prices increases in the share of RTP consumers.

Proof: We proceed in two steps. First, we show that $\frac{d \mathbb{E}\left(C S_{F P}\right)}{d t}>0$. Second, we confirm that $\frac{d \Delta\left(\beta_{t}, n, t\right)}{d t}>0$. The second condition implies that also $\frac{d \mathbb{E}\left(C S_{R T P}\right)}{d t}>0$. First, surplus of consumers on fixed prices always increases in $t$,

$$
\frac{d \mathbb{E}\left(C S_{F P}\right)}{d t}=\frac{\partial \mathbb{E}\left(C S_{F P}\right)}{\partial \beta_{t}} \frac{\partial \beta_{t}}{\partial t} \Longleftrightarrow \frac{d \mathbb{E}\left(C S_{F P}\right)}{d t}=\frac{(3-2 a)^{2} \beta_{t} n^{2}}{4\left(\beta_{t} n+1\right)^{3}} \frac{\partial \beta_{t}}{\partial t}>0
$$

Second, for the difference in surplus we have

$$
\begin{gathered}
\frac{d \Delta\left(\beta_{t}, n, t\right)}{d t}=\frac{\partial \Delta\left(\beta_{t}, n, t\right)}{\partial t}+\frac{\partial \Delta\left(\beta_{t}, n, t\right)}{\partial \beta_{t}} \frac{\partial \beta_{t}}{\partial t} \\
\Longleftrightarrow \frac{d \Delta\left(\beta_{t}, n, t\right)}{d t}=\frac{\beta_{t} n+t-1}{12\left(\beta_{t} n+1\right)^{3}}+\frac{n\left(\beta_{t} n+t-1\right)}{12\left(\beta_{t} n+1\right)^{3}} \frac{\partial \beta_{t}}{\partial t}>0 .
\end{gathered}
$$


The inequality holds because, using $\beta_{t}$ in equation (10) and $n>2$, it can be shown that $\beta_{t} n+t>1$, so that both nominators are always positive.

The result that both consumer groups experience positive externalities as the share of RTP consumers increases differs from Borenstein and Holland (2005) and is in line with Poletti and Wright (2020). Specifically, we show that also incumbent RTP consumers experience a positive externality, which results from a lower price volatility on the wholesale market. Whether these externalities are realized, of course, depends on whether other households opt into RTP contracts.

Finally, we therefore compare the consumer surplus between the two groups and establish our main result on the incentives to participate in RTP.

Proposition 5 Given any $t \in[0,1]$, the expected surplus of consumers on real-time pricing is always lower than the surplus of consumers on traditional meters with fixed retail prices. This difference in surplus decreases as $t$ approaches 1.

Proof: We show that $\Delta\left(\beta_{t}, n, t\right)<0$ for all $t \in[0,1]$. Recalling that $\Delta\left(\beta_{t}, n, t\right)=\frac{1-2\left(\beta_{t} n+t\right)}{24\left(\beta_{t} n+t\right)^{2}}$ and using $\beta_{t} n+t>1$ from our previous proof, $\Delta\left(\beta_{t}, n, t\right)<0$ follows. Because from Proposition 4 it also holds that $\frac{d \Delta\left(\beta_{t}, n, t\right)}{d t}>0$, the difference in surplus $\Delta\left(\beta_{t}, n, t\right)$ is always negative but increases in $t$.

The finding that RTP consumers are always worse off as compared to consumers on fixed prices shows the existence of a public good dilemma for demand response in power markets: while welfare increase for higher shares of price-reactive consumers, each individual consumer is better off when remaining on time-invariant contracts and other households instead are opting into RTP. The second part of Proposition 4 furthermore illustrates that the difference in utility decreases in $t$, implying that especially the first households who consider switching to RTP suffer from relatively higher dis-utility as compared to households who sign RTP contracts for an already high market roll-out of RTP, i.e., for $t$ close to 1 . 


\section{$5 \quad$ Regulatory implications}

Our results so far show that (i) larger market shares of consumers on real-time pricing raise welfare, (ii) real-time pricing increases the surplus of retail consumers and incumbent RTP consumers (i.e., each household who opts into RTP contracts exhibits a positive externality on both consumer groups), and (iii) switching to RTP contracts is, however, not incentive compatible when consumers are risk-averse.

From a regulatory perspective, these findings suggest two possibilities. First, regulators could opt for a mandate for real-time pricing to overcome this dilemma. Second, regulators and retail firms could seek for more elaborate retail contract designs (e.g., Borenstein, 2013). In this case, retail contracts could also implicitly introduce side-payment mechanisms. For instance, retail companies could design contracts that cross-subsidize each household that switches to RTP by adding mark-ups for consumers on fixed prices, that receive the positive externality.

Note that to justify such regulatory mandates, aggregate consumer surplus should increase. Similarly, also for side-payment mechanisms to be feasible, aggregate consumer surplus must increase (i.e., the benefits of the externality must outweigh the loss of the switching household to allow for such cross-subsidies to be implementable). Therefore, we in closing explore the possibilities for these strategies and investigate the overall changes in consumer surplus.

To see the contradicting forces of RTP on aggregate consumer surplus, note that the total expected consumer surplus in the market can be written as

$$
\mathbb{E}(C S)=t \mathbb{E}\left(C S_{R T P}\right)+(1-t) \mathbb{E}\left(C S_{F P}\right)
$$

Contradicting forces exist because while both types of consumers benefit from an increase in the ratio of real-time pricing, the marginal household always loses. Therefore, the overall 
change in surplus depends on the net-effect of these two forces. The impact of a larger share of consumers on RTP on the expected total consumer surplus can be written as

$$
\frac{d \mathbb{E}(C S)}{d t}=\mathbb{E}\left(C S_{F P}(t)\right)-\mathbb{E}\left(C S_{R T P}(t)\right)+t \frac{\partial \mathbb{E}\left(C S_{R T P}\right)}{\partial t}+(1-t) \frac{\partial \mathbb{E}\left(C S_{F P}\right)}{\partial t}
$$

The first two terms on the right-hand side represent the effect on the marginal household switching to RTP, which is always negative due to Proposition 5. The third and fourth term on the right hand side represent the externalities on the infra-marginal consumers of either type. These two terms are always positive due to Proposition 4.

Whereas we have explored conditions that characterize the net-effects of RTP, closed form solutions quickly become untractable. We therefore simulate effects on total consumers surplus in Figure 2. Figure 2 plots the aggregate consumer surplus over the share of RTP consumers $t \in[0,1]$ and over the convexity of supply. Convexity of supply is defined as $k \in[0,1]$ with $k=b / \bar{b}$, see equation (17), so that $k=1$ represents the steepest possible supply. In contrast, $k=0$ represents a flat supply curve. We set $a=0.5$. The results do not differ by much when choosing different supply intercepts. We plot consumer surplus for an imperfect market with $n=3$ and for a competitive market with $n=30$.

As can be seen, the results substantially differ when increasing the share of RTP consumers for these two cases. In the left part of Figure 2, for $n=3$, increasing the share of consumers on real-time pricing increases aggregate consumer surplus, especially if market supply is very steep and $k$ is close to 1 . In contrast, in competitive markets, as shown in the right part of Figure 2, the total consumer surplus decreases in the share of RTP consumers, again especially for $k$ close 1 . In addition, both graphs confirm that consumer surplus increases if supply becomes flatter ( $k$ approaches 0$)$.

The patterns in Figure 2 stress the consumer value of RTP especially for imperfect power markets. The additional surplus for this case largely results from cushioning market 

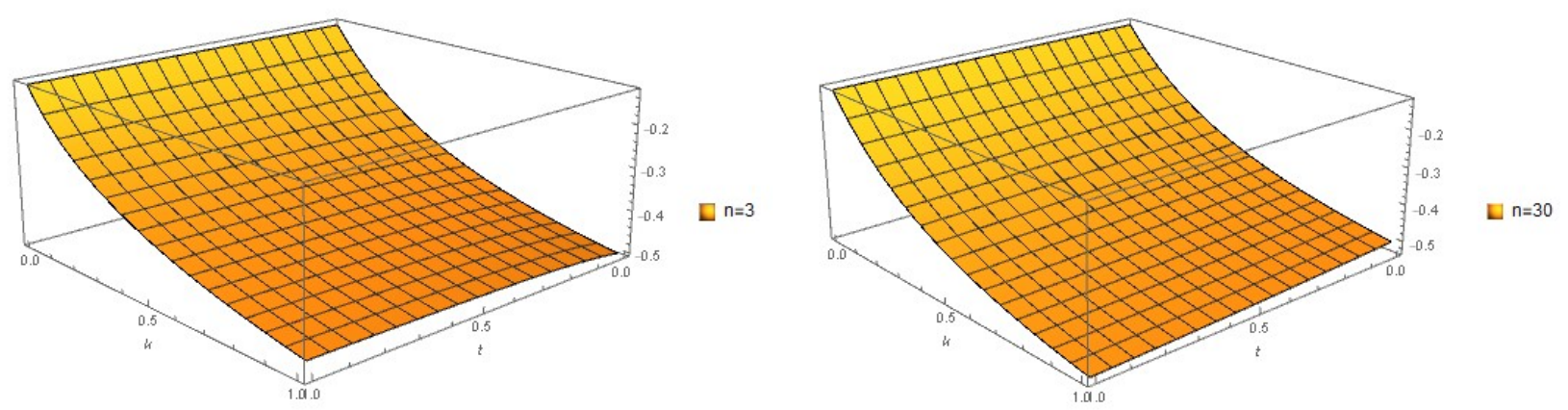

Figure 2: Total consumer surplus for $a=0.5$. The left graph shows consumers surplus over the convexity parameter $k$ and the share of RTP consumers $t$ for $n=3$. The right graph shows consumer surplus over $k$ and $t$ for $n=30$.

power via RTP (changing the strategic supply slope $\beta_{t}$ ). If, in contrast, power markets are relatively competitive already, this positive effect on consumers does not realize. Instead RTP consumers merely face contracts with volatile and risky market prices, decreasing their surplus. In sum, Figure 2 shows that RTP policies are promising for consumers and regulators especially in imperfect power markets.

To further characterize the value of RTP for differently concentrated markets, we compare total consumer surplus without any consumer on RTP $(t=0)$ with the total consumer surplus if all consumers are on RTP $(t=1)$. Forcing all consumers on RTP, given that none of them are on RTP before, will only be an option for regulators if

$$
C S_{F P}(t=0) \leq C S_{R T P}(t=1)
$$

holds. This condition is illustrated in Figure 3 and depends on the cost parameters $(a, k) \in$ $[0,1] \times[0,1]$ as well as on the number of competitors.

For $C S_{F P}(t=0) \leq C S_{R T P}(t=1)$ to hold, the parameter combination $(a, k)$ must be below the respective threshold shown in Figure 3, which we plot for $n=3,5,7,10$. Intuitively, if the convexity of supply $k$ is large, using the RTP mandate to decrease markups becomes relatively more beneficial. As can be seen, the parameter space for which 


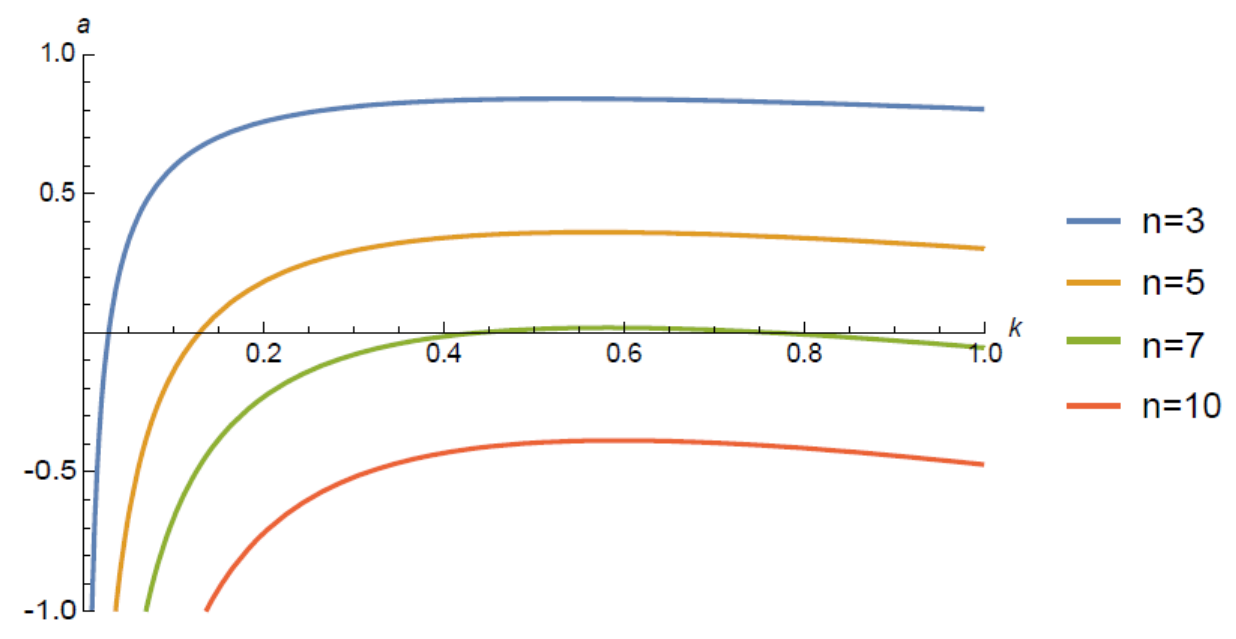

Figure 3: Condition on cost parameters $a$ and $k$ for which having all consumers on RTP yields higher total consumer surplus than having all consumers on fixed retail prices, plotted for different numbers of competitors $n$.

total consumer surplus increases if all consumers are forced into RTP becomes smaller for a higher number of competitors. With more than ten competitors, total consumer surplus is always higher if regulators do not force all consumers on RTP. However, with relatively few competitors and if convexity of supply is high, mandating a full roll-out of RTP is beneficial for consumers. While Figure 3 thus corroborates our previous findings, it in addition highlights that using RTP to decrease market power is especially attractive in markets with relatively steep aggregate supply curves.

\section{Conclusion}

While the use of smart meters is growing in power markets around the globe, the share of consumers on real-time pricing remains negligible. In this paper, we have derived formal results that explain the slow market diffusion of real-time pricing. When electricity generating firms have market power in the wholesale market and consumers are risk-averse, we show 
that real-time pricing increases the consumer surplus for each type of consumer, i.e., those on fixed retail prices and of incumbent RTP consumers. As a consequence, each consumer who opts for real-time pricing exhibits a positive externality on both consumer groups. Consumer surplus, however, is always higher for traditional consumers with fixed retail prices than for consumers on real-time pricing. Consequently, risk-averse consumers do not have incentives to switch to RTP. Since at the same time social welfare is increasing in the level of RTP, this result points to a public good dilemma.

Our findings confirm that real-time pricing is beneficial but suggest that regulatory effort has to be spent to overcome the public good nature of increasing demand response in power markets. Regulatory policies always increase social welfare but can only increase total consumer surplus in concentrated power markets, where RTP schemes cushion strategic mark-ups. If power markets are competitive, the benefits of reducing mark-ups can only be moderate and then are outweighed by increased risk exposure. To conclude, our results also

show that retail contract design and regulatory mechanisms need to account for risk-aversion to facilitate further market penetration of RTP contracts.

\section{References}

Allcott, Hunt (2011) "Rethinking Real Time Electricity Pricing," Resource and Energy Economics, Vol. 33, pp. $820-842$.

Baldick, Ross, Ryan Grant, and Edward Kahn (2004) "Theory and Application of Linear Supply Function Equilibrium in Electricity Markets," Journal of Regulatory Economics, Vol. 25, No. 2, pp. 143-167.

Boisvert, Richard N., Peter Cappers, Charles Goldman, Bernie Neenan, and Nicole Hopper (2007) "Customer Response to RTP in Competitive Markets: A Study of Niagara Mohawk's Standard Offer Tariff," The Energy Journal, Vol. 28, No. 1, pp. 53-74. 
Boom, Anette (2009) "Vertically Integrated Firms' Investments in Electricity Generating Capacities," International Journal of Industrial Organization, Vol. 27, pp. 544-551.

Boom, Anette and Stefan Buehler (2020) "Vertical Structure and the Risk of Rent Extraction in the Electricity Industry," Journal of Economics and Management Strategy, Vol. 29, No. 1, pp. 210-237.

Borenstein, Severin (2005) "The Long-run Efficiency of Real-time Electricity Pricing," The Energy Journal, Vol. 26, No. 3, pp. 93-116.

_ (2013) "Effective and equitable adoption of opt-in residential dynamic electricity pricing," Review of Industrial Organization, Vol. 42, No. 2, pp. 127-160.

Borenstein, Severin and James B. Bushnell (2019) "Do Two Electricity Pricing Wrongs Make a Right? Cost Recovery, Externalities and Efficiency," Energy Institute Working Paper 294R, Energy Institute at Haas, University of California, Berkeley, CA.

Borenstein, Severin and Stephen Holland (2005) "On the Efficiency of Competitive Electricity Markets with Time-invariant Retail Prices," The Rand Journal of Economics, Vol. 36, No. 3, pp. 469-493.

Campillo, Javier, Erik Dahlquist, Fredrik Wallin, and Iana Vassileva (2016) "Is Real-time Electricity Pricing Suitable for Residential Users without Demand-side Management?" Energy, Vol. 109, pp. 310-325.

Crew, Michael A., Chitru S. Fernando, and Paul R. Kleindorfer (1995) "The Theory of Peak-load Pricing: A Survey," Journal of Regulatory Economics, Vol. 8, No. 4, pp. 215-248.

European Commission (2014) "Benchmarking Smart Metering Deployment in the EU-27 with a Focus on Electricity," report from the commission, European Commission.

Green, Richard J. and David M. Newbery (1992) "Competition in the British Electricity Spot Market," Journal of Political Economy, Vol. 100, No. 5, pp. 929-953.

Holland, Stephen P. and Erin T. Mansur (2006) "The Short-run Effects of Time-Varying Prices in Competitive Electricity Markets," The Energy Journal, Vol. 27, No. 3, pp. 127-155.

Holmberg, Pär and David Newbery (2010) "The supply function equilibrium and its policy implications for wholesale electricity auctions," Utilities Policy, Vol. 18, No. 4, pp. 209-226. 
Horowitz, Shira and Lester Lave (2014) "Equity in residential electricity pricing," The Energy Journal, Vol. 35 , No. 2.

Hortacsu, Ali and Steven L. Puller (2005) "Understanding Strategic Bidding in Restructured Electricity Markets: A Case Study of ERCOT," Working Paper 11123, National Bureau of Economic Research, Cambridge, MA.

Hortacsu, Ali and Steven L Puller (2008) "Understanding strategic bidding in multi-unit auctions: a case study of the Texas electricity spot market," The RAND Journal of Economics, Vol. 39, No. 1, pp. 86-114.

Hung, Ming-Feng, Bin-Tzong Chie, and Huei-Chu Liao (2020) "A Comparison of Electricity-Pricing Programs: Economic Efficiency, Cost Recovery, and Income Distribution," Review of Industrial Organization, Vol. 56, No. 1, pp. 143-163.

Jessoe, Katrina and David Rapson (2014) "Knowledge is (less) power: Experimental evidence from residential energy use," American Economic Review, Vol. 104, No. 4, pp. 1417-38.

Joskow, Paul and Jean Tirole (2006) "Retail Electricity Competition," The Rand Journal of Economics, Vol. 37, No. 4, pp. 799-815.

_ (2007) "Reliability and Competitive Elextricity Markets," The Rand Journal of Economics, Vol. 38, No. 4 , pp. $60-84$.

Joskow, Paul L. and Catherine D. Wolfram (2012) "Dynamic Pricing of Electricity," The American Economic Review: Papers 8 Proceedings, Vol. 102, No. 3, pp. 381-385.

Klemperer, Paul D. and Margeret A. Meyer (1989) "Supply Function Equilibria in Oligopoly under Uncertainty," Econometrica, Vol. 57, No. 6, pp. 1243-1277.

Léautier, Thomas Olivier (2014) "Is Mandating "Smart Meters" Smart?" The Energy Journal, Vol. 35, No. 4, pp. 135-157.

Patrick, Robert and Frank A. Wolak (2001) "Estimating the Customer-level Demand for Electricity under Real-time Market Prices," Working Paper 8213, National Bureau of Economic Research, Cambridge, MA.

Poletti, Stephen and Julian Wright (2020) "Real-Time Pricing and Imperfect Competition in Electricity Markets," The Journal of Industrial Economics, Vol. 68, No. 1. 
Qiu, Yueming, Gregory Colson, and Michael E. Wetzstein (2017) "Risk Preference and Adverse Selection for Participation in Time-of use Electricity Pricing Programs," Resource and Energy Economics, Vol. 47, pp. $126-142$.

Taylor, Thomas N., Peter M. Schwarz, and James E. Cochell (2005) "24/7 Hourly Response to Electricity Real-Time Pricing with up to Eight Summers of Experience," Journal of Regulatory Economics, Vol. 27, No. 3, pp. 235-262.

Wilson, Robert (1979) "Auctions of shares," The Quarterly Journal of Economics, pp. 675-689.

Wolak, Frank A (2015) "Do customers respond to real-time usage feedback? Evidence from Singapore,"Technical report, Working Paper.

Zarnikau, Jay and Ian Hallett (2008) "Aggregate Industrial Energy Consumer Response to Wholesale Prices in the Restructured Texas Electricity Market," Energy Economics, Vol. 30, pp. 1798-1808. 